\title{
Sistem Kunci Pintu Otomatis Kelas Perkuliahan Berbasis Android Terintegrasi Sistem Informasi Akademik
}

\author{
HERIANSYAH, RAHMAN ECKY R, DIANA ANGGRAENI S, \\ SWADEXI ISTIQPHARA
}

Institut Teknologi Sumatera

Email: heri@el.itera.ac.id

Received 1 Oktober2020 | Revised 15 November 2020 | Accepted 28 November 2020

\begin{abstract}
ABSTRAK
Kunci pintu otomatis menawarkan kemudahan untuk mengakses ruangan dengan cara yang lebih efektif dan efisien dibandingkan dengan metode konvensional. Pada penelitian ini sistem kunci pintu otomatis menggunakan $Q R$ code dari aplikasi Pocket ITERA yang berbasis Android yang terintegrasi dengan Sistem Informasi Akademik (Siakad). Metode penelitian yang digunakan yaitu studi literatur mengenai kunci pintu otomatis, eksplorasi, dan spesifikasi alat. Adapun metode analisisnya yaitu analisis kebutuhan dan analisis operasional hardware dan software. Hasil implementasi rancangan menghasilkan sebuah perangkat kunci pintu otomatis berbasis IoT dan dapat dibuka dengan aplikasi Pocket ITERA di mana keduanya berkomunikasi secara realtime dengan database Siakad. Sistem ini berhasil dijalankan dengan baik sehingga pemanfaatan ruang kelas menjadi optimal dan berjalan sesuai jadwal yang telah ditentukan.
\end{abstract}

Kata kunci: Android, Kunci Pintu Otomatis, QR Code, Sistem Informasi

\begin{abstract}
Automatic door locks offer convenience to access the room in a more effective and efficient way compared to conventional methods. In this study, an automatic door lock system using a QR code from the Pocket ITERA application based on Android that is integrated with the Academic Information System (Siakad). The research method used is the study of literature on automatic door locks, exploration, and determining tool specifications. The methods of analysis are need and operational analysis of hardware \& software. The results of the design implementation produce an IoT-based automatic door lock device and can be opened with the Pocket ITERA application where both communicate in real time with the Siakad database. Furthermore, this system successfully implemented, hence the utilization of the classrooms became optimal and runs according to a predetermined schedule.
\end{abstract}

Keywords: Automatic Door Lock, Android, IOT, QR code, Infromation System 


\section{PENDAHULUAN}

Pintu merupakan lapisan pertama yang melindungi isi dari ruangan dan salah satu akses masuk dan keluar yang membutuhkan tingkat keamanan yang tinggi (Haryanto, 2019). Keamanan ruangan merupakan suatu hal yang sangat penting untuk mengamankan barang-barang berharga yang berharga yang berada didalam ruangan dan mencegah pemakaian ruangan kelas yang tidak sesuai prosedur (Juniawan \& Sylfania, 2019). Institut Teknologi Sumatera merupakan kampus yang sering mengalami perubahan jadwal yang secara mendadak sehingga sering terjadi tindak pemakaian ruangan yang tidak terjadwal atau tidak sesuai prosedur. Oleh karena itu sebuah sistem kunci keamanan sangatlah penting pada ruang-ruang kelas yang terdapat di Institut Teknologi Sumatera.

Saat ini Pintu kelas di Institut Teknologi Sumatera (ITERA) masih menggunakan pengamanan dengan kunci konvensional seperti yang banyak digunakan oleh masyarakat. Seperti yang diketahui kunci konvensional mudah sekali dilumpuhkan oleh pelaku tindak kejahatan. Selain itu, dengan menggunakan kunci konvensional dalam sistem pengamanan juga kurang terpercaya karena kunci konvensional mudah hilang dalam penggunaannya, sehingga sistem ini dirasa kurang praktis dan rentan terhadap tindakan pencurian (Iskandar, Muhajirin, \& Lisah, 2017). Untuk mengatasi permasalahan tersebut maka diperlukan sebuah sistem kunci pintu yang lebih modern yakni dengan menggabungkan komponen elektronik berbasis IoT yang diatur menggunakan mikrokontroler dan aplikasi POCKET ITERA yang diintegrasikan dalam server database kampus. POCKET ITERA sendiri merupakan sebuah aplikas berbasis Android yang dapat digunakan untuk mengakses keperluan akademik maupun nonakademik yang hanya bisa digunakan oleh civitas akademik ITERA. Sistem kunci pintu yang dirancang diberi nama AUDOCKPORA (Automatic Door Lock System Berbasis Android Menggunakan POCKET ITERA), sistem ini nantinya memiliki fungsi utama untuk membuka pintu ruang kelas yang ada di lingkungan kampus dengan memanfaatkan $Q R$ Scanner untuk memindai Quick Response $(Q R)$ code dari aplikasi POCKET ITERA yang terhubung ke server SIAKAD kampus. Selain memiliki fitur utama sistem AUDOCKPORA juga memiliki fitur alternatif untuk membuka pintu ketika fitur utama mengalami gangguan, fitur tersebut berupa penggunaan Radio-Frequency Identification (RFID) sebagai master key. Terdapat pula fitur tambahan push button door exit untuk membuka pintu dari dalam kelas serta fitur untuk mendeteksi ketika pintu dibuka paksa tanpa melalui akses utama atau alternatif. Untuk merealisasikan sistem kunci pintu AUDOCKPORA tersebut maka dibutuhkan rancang bangun untuk mengimplementasikan fungsi utama dan fungsi alternatif AUDOCKPORA. Selanjutnya sistem AUDOCKPORA digabungkan menjadi satu dengan fungsi alternatif (master key) untuk membuka pintu dengan RFID.

\section{METODE PENELITIAN}

\subsection{Kunci Pintu Otomatis}

Kunci pintu otomatis merupakan salah satu bentuk kontrol untuk sistem membuka dan mengunci pintu. Biasanya sistem ini sering diterapkan pada gedung-gedung perkantoran yang menggunakan kartu identitas agar pintu bisa terbuka, dimana kartu identitas berisi data Unix sebagai kontrol akses pintu (Lonika \& Hariyanto, 2019). Umumnya sistem kunci otomatis menggunakan kontrol akses fisik seperti 
menggunakan sidik jari, password, ketukan, RFID bahkan menggunakan jaringan internet (Asad, Nurhayati, \& Widianto, 2015).

Kunci pintu otomatis yang ada di pasaran menggunakan alat pengunci yang beroperasi dengan arus listrik, kunci listrik ini dibuat agar dapat dihubungkan ke sistem kontrol akses. Salah satu contoh kunci elektrik yang sering digunakan adalah solenoid door lock. Solenoid door lock memiliki prinsip kerja dengan memanfaatkan medan magnet untuk membuka pintu, Di dalam solenoid terdapat kawat yang melingkar pada inti besi. Ketika arus listrik mengalir melalui kawat ini, maka terjadi medan magnet untuk menghasilkan energi yang akan menarik inti besi ke dalam (Guntoro, Costaner, \& Sutejo, 2017).

\subsection{QR Code}

$Q R$ code (Quick Response code) merupakan sebuah produk dagang berjenis barcode matrix 2 dimensi yang pertama kali dirancang pada tahun 1994 untuk industri otomotif di Jepang. Barcode merupakan machine-readable yang berisi informasi tentang item yang dilampirkan. Umumnya kode QR berisi data lokasi, identitas, atau pun berisikan halaman website atau aplikasi. Kode QR menggunakan empat standar encoding yakni numerik, alfanumerik, byte/biner dan kanji untuk menyimpan data secara efisien (Saghranie Daulay, 2011). Secara statistik kode QR dapat menyandingkan jumlah data yang sama di sekitar sepersepuluh ruang penyimpanan yang digunakan pada barcode traditional 1 dimensi.

Arsitektur kode QR berisi area yang ditentukan sebagai reversed function, agar mudah dipahami pembaca dan pengguna untuk mengetahui tujuan, pola fungsional, perancangan dan penggunaan quick response code (QR). Kode QR terdiri dari berbagai area yang disediakan untuk tujuan tertentu. Pola pencari, pola pemisah, pengaturan waktu dan pola pelurusan menentukan pola fungsi, yang tidak digunakan untuk menyandikkan data (Blasinski, Bulan, \& Sharma, 2013).

\subsection{Sensor GM-65 (QR Scanner)}

Sensor GM65 merupakan modul $Q R$ scanner yang memiliki high performance dalam pembacaan, sensor ini dapat membaca kode batang 1D dan kode batang 2D dengan kecepatan yang tinggi. Dari segi kecepatan dalam memindai kode linier modul ini lebih cepat, bahkan untuk kode batang pada kertas atau layar. Modul GM65 adalah algoritma decoding barcode canggih yang dikembangkan pada algoritma pengenalan gambar, dapat dengan mudah dan akurat membaca kode batang, menyederhanakan pengembangan sekunder. MG65 bekerja stabil di kisaran suhu gelap dan besar (Hangzhou, 2016). Sensor GM-65 mempunyai keluaran sensor berupa heksadesimal yang harus diubah oleh microcontroller Arduino menjadi sebuah karakter teks ASCII. Dalam kaidah nya sensor tersebut memiliki karakteristik tersendiri. Hal ini disebabkan sensor GM-65 tidak hanya dapat mendeteksi barcode 2 dimensi melainkan 1 dimensi. Communication interface dari sensor GM-65 dengan menggunakan SD-MG1S02 yang dapat menerima basis data, modul control dan mengatur parameter fungsional dengan TTL-23 (Hangzhou, 2016). Series Communication interface dari Sensor GM-65 dengan PC atau hardware menggunakan TTL-232 dan diperlukan sirkuit pengganti untuk RS-232. Terdapat 3 cara communication interface yaitu series communication interface, USB Interface, USB Virtual Serial Port. 


\subsection{Arduino Mega 2560}

Arduino merupakan microcontroller yang memiliki komponen utama yakni sebuah microprocessor dengan jenis avr yang dibuat oleh perusahan atmel. Arduino memiliki banyak sekali varian salah satunya adalah arduino mega bertipe 2560 seperti Gambar 2, tipe ini adalah salah satu microcontroller berbasis arduino dengan chip atmega 2560. Arduino mega 2560 memiliki 54 buah pin digital i/o (terdiri dari 15 pin pwm), 16 pin analog input, 4 pin uart (serial port). Board ini dilengkapi dengan oscillator sebesar 16 mhz, port usb, power jack $d c$, icsp header, dan reset button (Robotshop, 2015).

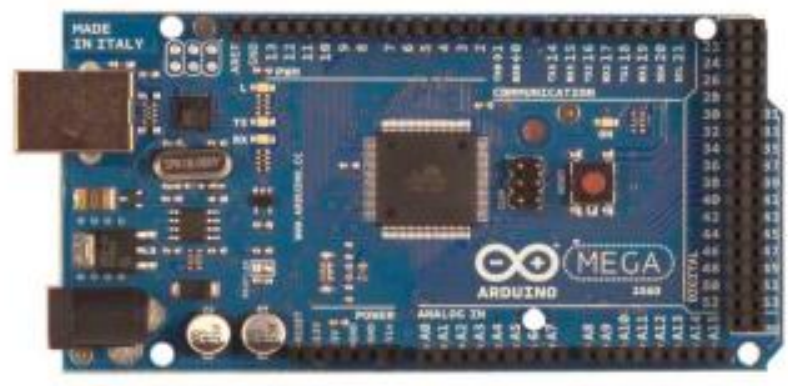

Gambar 1. Arduino Mega 2560 (Robotshop, 2015)

\subsection{Aplikasi Pocket ITERA}

Aplikasi POCKET ITERA merupakan aplikasi yang dibuat oleh UPT TIK ITERA. Aplikasi ini dibuat guna memudahkan civitas akademik di lingkungan ITERA untuk mengakses informasi dan layanan akademik. Pada aplikasi POCKET ITERA terdapat fitur-fitur terkait informasi dan pelayanan akademik seperti, fitur akademik, lapor kondisi kesehatan, help desk, ITERA news, izin kegiatan, e-learning, transkrip nilai dan lainlain. Dalam pengembangannya POCKET ITERA telah mengalami beberapa kali peningkatan versi, dimana peningkatan ini dilakukan untuk memperbaiki bug ataupun untuk menambahkan fitur-fitur terbaru untuk menunjang kegiatan di lingkungan kampus ITERA. POCKET ITERA sendiri untuk saat ini baru dikembangkan untuk sistem operasi berbasis android, dimana Android merupakan sebuah sistem operasi yang bersifat open source berbasis Linux dirancang untuk perangkat seluler layar sentuh (touchscreen) seperti smartphone dan tablet (Tutorialpoint, 2014).

\subsection{Perancangan Sistem Analisis Kebutuhan Hardware}

Pada fungsi utama sistem AUDOCKPORA ini diperlukan beberapa perangkat keras yang dapat menunjang kebutuhan sistem. Perangkat yang digunakan pada fungsi utama yang dibutuhkan yakni, sensor $Q R$ scanner untuk menghasilakan $Q R$ code dan microcontroller yang dapat diintegrasikan dengan sensor $Q R$ scanner. Selain kedua perangkat utama tersebut pada sistem ini juga diperlukan perangkat tambahan seperti buzzer sebagai bunyi notifikasi ketika pintu di akses, LCD sebagai interface pengguna, tombol untuk akses pintu dari dalam kelas ketika akan keluar ruangan, modul internet untuk berkomunikasi ke database, dan yang tak kalah penting yakni catu daya yang digunakan sebagai penyuplai daya sistem. Pada supply, selain supply primer dari listrik PLN juga diperlukan supply sekunder sebagai back up sementara ketika supply primer mengalami gangguan/padam listrik. Untuk fungsi alternatif untuk akses masuk pintu kelas dan sistem detector pintu dibuka paksa pada AUDOCKORA menggunakan RFID 
dan sensor button, namun fungsi alternatif dan detector tersebut akan dibahas pada makalah berikutnya yang membahas mengenai sistem RFID dan detector pintu ketika dibuka paksa.

\subsection{Perancangan Sistem Analisis Kebutuhan Software}

Selain kebutuhan hardware, AUDOCKPORA didukung oleh komponen software yang berfungsi untuk menghasilkan $Q R$ Code yang berisi data-data yang didapat dari database Siakad. Beberapa komponen yang dibutuhkan yakni hak akses untuk mengakses database Siakad dan antar muka pengguna yang berisi tata letak aplikasi yang terdiri dari tata letak untuk menampilkan kelas, dan tata letak untuk menggenerate $Q R$ code untuk mengakses kelas.

\subsection{Perancangan Sistem Analisis Teknis Operasional Sistem Hardware}

Diagram sistem hardware pada sistem rancang bangun kunci pintu otomatis menggunakan $Q R$ code ini ditunjukkan pada Gambar 2.

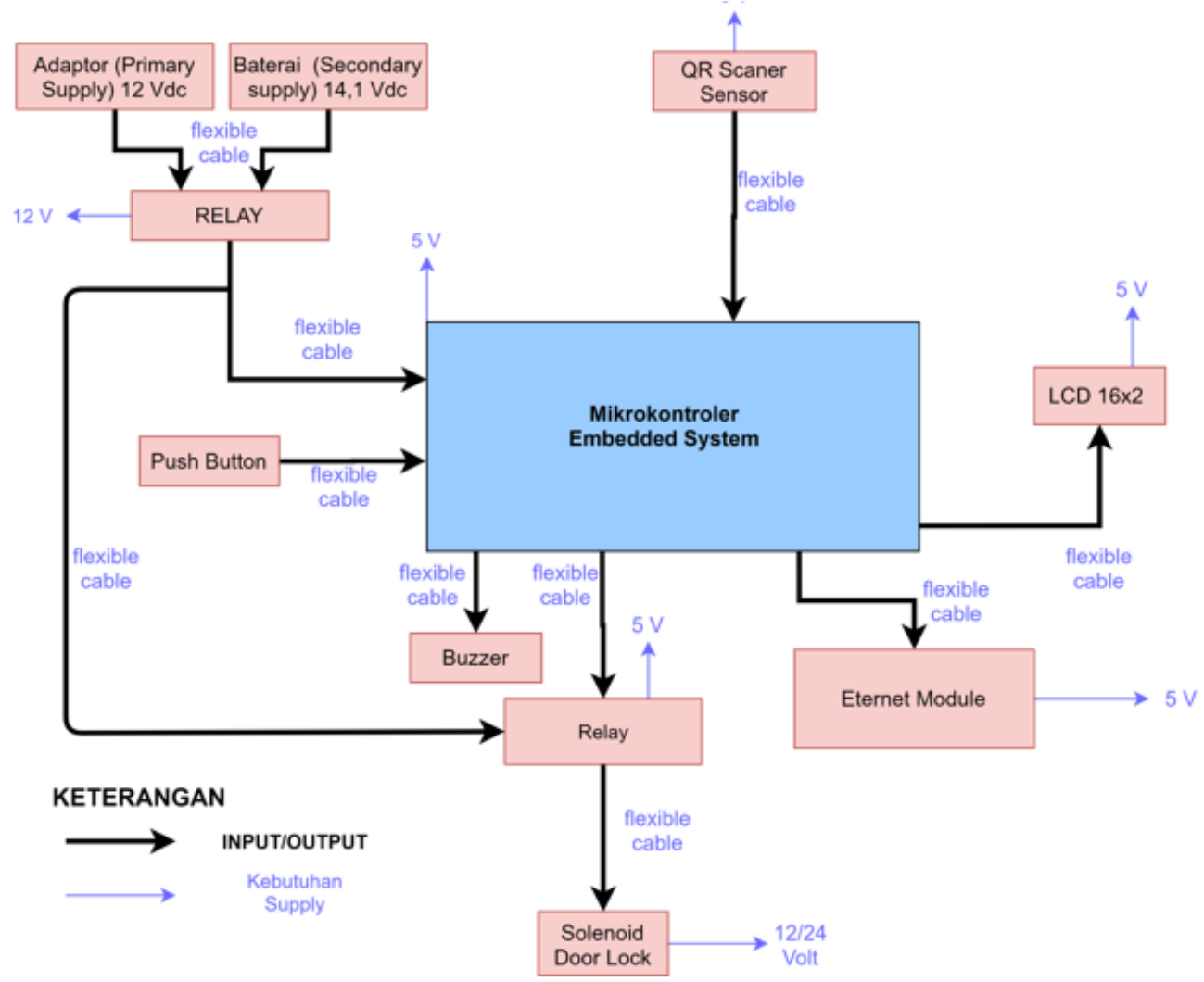

Gambar 2. Diagram Sistem Hardware

\subsection{Perancangan Fisik}

Desain alat yang buka kunci pintu otomatis menggunakan $Q R$ code ini nantinya akan digabungkan dengan alat kunci pintu otomatis menggunakan RFID beserta alat detector pintu yang dibuka secara paksa. Alat ini nantinya dikemas dalam bentuk kotak berbahan plastik dengan warna hitam berukuran $18,5 \mathrm{~cm} \times 11.5 \mathrm{~cm} \times 6,5$. Kemudian rancang bangun alat yang dibuat akan diletakkan di samping pintu kelas yang berada 
di gedung perkuliahan di Institut Teknologi Sumatera. Desain perancangan fisik alat dan peletakannya dapat dilihat seperti pada sketsa 3D Gambar 3 dan Gambar 4.

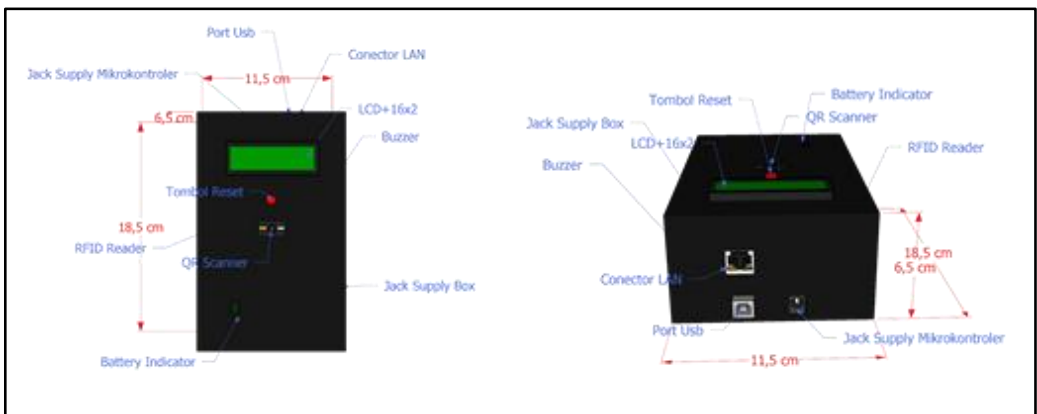

Gambar 3. Sketsa 3D Packaging Alat
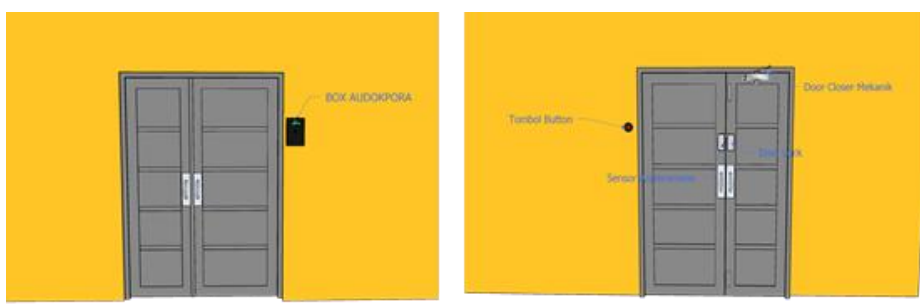

Gambar 4. Sketsa 3D Peletakkan Alat

3. HASIL DAN PEMBAHASAN

\subsection{Implementasi Hardware}

Hasil implementasi sistem hardware yang telah di kemas dalam packaging dapat dilihat seperti pada Gambar 5.

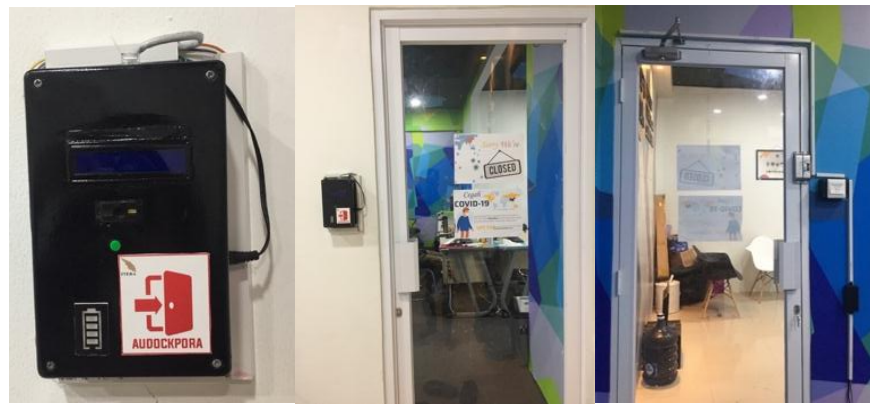

Gambar 5. Hasil Implementasi Hardware

Implementasi sistem buka kunci pintu otomatis ini dibuat dalam bentuk kotak berbahan plastik dengan warna hitam berukuran 18,5 cm x $11.5 \mathrm{~cm} \times 6,5$ (Gambar 5) yang diletakkan di samping pintu kelas yang berada di gedung perkuliahan. Pengunci pintu yakni solenoid door lock diletakkan di bagian sisi pintu dan kusen bagian dalam kelas sedangkan tombol door exit diletakkan di bagian dalam kelas tepat di samping pintu kelas. Selain itu, juga disediakan engsel hidrolik yang digunakan sebagai alat bantu untuk menutup kembali pintu setelah pintu dibuka. Sistem ini menggunakan dua 
jenis catu daya yaitu catu daya primer yang didapat dari aliran listrik PLN dan sekunder atau cadangan yang diperoleh dari baterai rechargeable 18650 dengan kapasitas 3.7 volt $3600 \mathrm{mAH}$ per selnya yang diletakkan di dalam kotak AUDOCKPORA.

\subsection{Implementasi Software}

Proses implementasi Perangkat lunak dilakukan dengan membuat antar muka aplikasi door lock yang kemudian ditambahkan pada sub menu more apps yang ada di aplikasi POCKET ITERA yang sudah dibuat sebelumnya. Cara kerja aplikasi ini ditunjukkan oleh Gambar 6. Pembuatan aplikasi ini dilakukan menggunakan bantuan software Android Studio yang mendukung pembuatan aplikasi berabasis Android. Hasil implementasi perangkat lunak dapat dilihat pada Gambar 7.

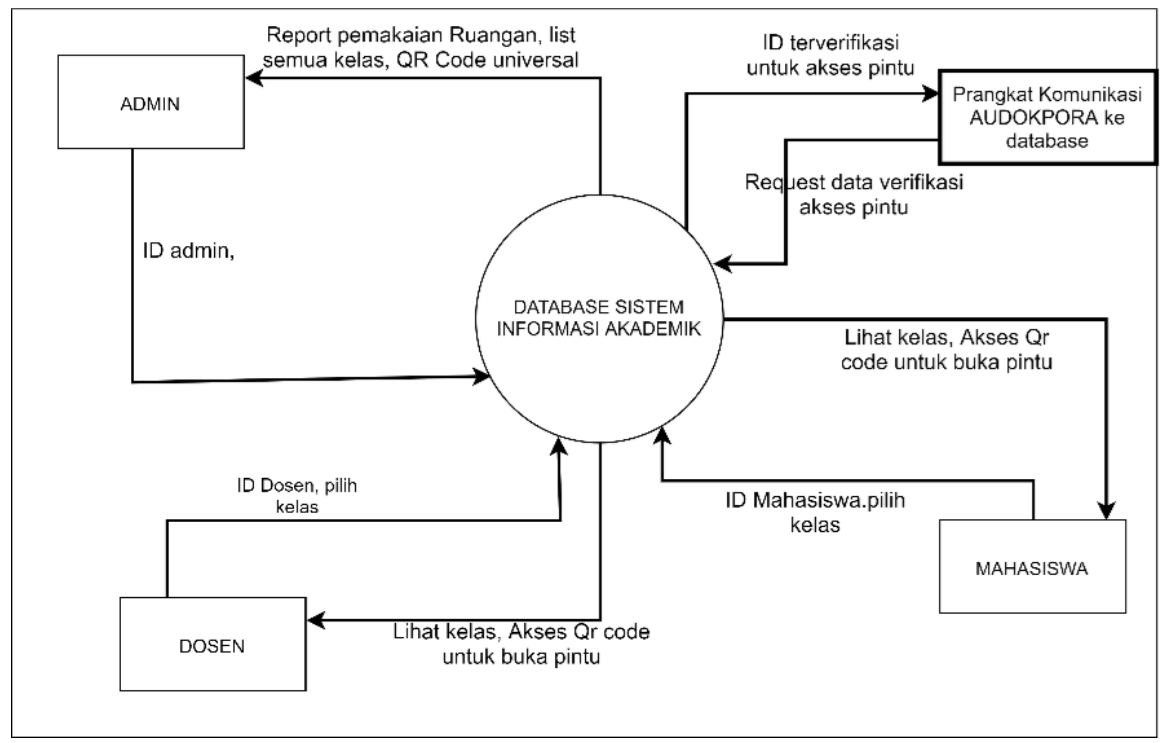

Gambar 6. Diagram Cara Kerja Aplikasi
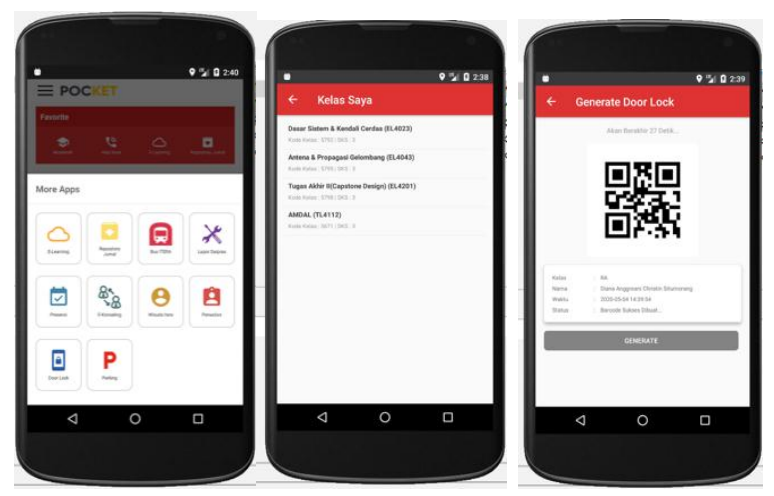

Gambar 7. Hasil Implementasi Software

\subsection{Hasil Pengujian}

Hasil pengujian yang dilakukan terdiri atas pengujian hardware dan pengujian software. Adapun hasil pengujian software dan hardware diuraikan dibawah ini.

\section{Pengujian Hardware}


Hasil pengujian hardware dilakukan dengan melakukan pengujian pada hasil scan QR code untuk buka kunci pintu, pengujian door exit, pengujian penggerak door lock dan notifikasi, pengujian LCD sebagai interface perangkat keras, dan pengujian modul Ethernet W5100 sebagai perangkat keras komunikasi database. Berikut hasil pengujian yang diperoleh.

Tabel 1. Pengujian Hasil Scan QR code untuk Buka Kunci Pintu

\begin{tabular}{|c|c|c|c|l|}
\hline No & $\begin{array}{c}\text { Hasil Scan QR Scanner } \\
\text { GM-65 }\end{array}$ & $\begin{array}{c}\text { Hasil Scan } \\
\text { Manual }\end{array}$ & $\begin{array}{c}\text { Verifikasi } \\
\text { Respon }\end{array}$ & $\begin{array}{c}\text { Respon Door } \\
\text { lock }\end{array}$ \\
\hline 1 & $\mathrm{db08f2}$ & $\mathrm{db08f2}$ & Authorized Access & Unlock \\
\hline 2 & $\mathrm{f} 642 \mathrm{fc}$ & $\mathrm{f} 642 \mathrm{fc}$ & Authorized Access & Unlock \\
\hline 3 & 123456 & 123456 & Akses Ditolak & Lock \\
\hline 4 & $615 \mathrm{~b} 0 \mathrm{c}$ & $615 \mathrm{~b} 0 \mathrm{c}$ & Authorized Access & Unlock \\
\hline 5 & Ah3456 & Ah3456 & Akses Ditolak & Lock \\
\hline 6 & $74 \mathrm{f} 200$ & $74 \mathrm{f} 200$ & Authorized Access & Unlock \\
\hline 7 & $03386 \mathrm{c}$ & $03386 \mathrm{c}$ & Akses Ditolak & Unlock \\
\hline 8 & $\mathrm{c} 1 \mathrm{c} 1 \mathrm{a} 2$ & $\mathrm{c} 1 \mathrm{c} 1 \mathrm{a} 2$ & Authorized Access & Unlock \\
\hline 9 & tras34 & tras34 & Akses Ditolak & Lock \\
\hline 10 & $5 \mathrm{~d} 5 \mathrm{~b} 2 \mathrm{c}$ & $5 \mathrm{~d} 5 \mathrm{~b} 2 \mathrm{c}$ & Akses Ditolak & Lock \\
\hline 11 & Ah3456 & Ah3456 & Akses Ditolak & Lock \\
\hline 12 & $96 f 063$ & $96 \mathrm{f063}$ & Authorized Access & Unlock \\
\hline 13 & eaf69c & eaf69c & Authorized Access & Unlock \\
\hline 14 & dfdbdb & dfdbdb & Authorized Access & Unlock \\
\hline 15 & gds45h & gds45h & Authorized Access & Unlock \\
\hline
\end{tabular}

Tabel 2. Pengujian Button "Door Exit"

\begin{tabular}{|c|c|c|c|}
\hline No. & Trigger Button & Akses & Door lock \\
\hline 1 & Low & Valid & Unlock \\
\hline 2 & High & tidak diakses & Lock \\
\hline 3 & Low & Valid & Unlock \\
\hline 4 & High & tidak diakses & Lock \\
\hline 5 & High & Valid & Unlock \\
\hline 6 & High & Valid & Unlock \\
\hline 7 & High & Valid & Unlock \\
\hline 8 & High & Valid & Unlock \\
\hline 9 & High & tidak diakses & Lock \\
\hline 10 & Low & & \\
\hline
\end{tabular}


Tabel 3. Pengujian Notifikasi Buzzer

\begin{tabular}{|c|c|c|c|c|}
\hline NO & $\begin{array}{c}\text { Akses yang } \\
\text { digunakan }\end{array}$ & Jenis akses & $\begin{array}{c}\text { Verifikasi akses } \\
\text { door lock }\end{array}$ & Bunyi Buzzer \\
\hline 1 & & $Q R$ code & Valid & Bunyi beep valid \\
\hline 2 & & $Q R$ code & Valid & Bunyi beep valid \\
\hline 3 & & $Q R$ code & Valid & Bunyi beep valid \\
\hline 4 & & $Q R$ code & Invalid & $\begin{array}{l}\text { Bunyi beep } \\
\text { invalid }\end{array}$ \\
\hline 5 & & $Q R$ code & Invalid & $\begin{array}{l}\text { Bunyi beep } \\
\text { Invalid }\end{array}$ \\
\hline 6 & Low & Button Exit & Valid & Bunyi beep valid \\
\hline 7 & High & Button Exit & - & - \\
\hline 8 & Low & Button Exit & Valid & Bunyi beep valid \\
\hline 9 & High & Button Exit & - & - \\
\hline 10 & Low & Button Exit & Valid & Bunyi beep valid \\
\hline
\end{tabular}

Tabel 4. Hasil Pengujian Solenoid Door lock

\begin{tabular}{|c|l|}
\hline $\begin{array}{c}\text { Tegangan Yang } \\
\text { Diberikan }\end{array}$ & \multicolumn{1}{c|}{ Respon Solenoid } \\
\hline $1 \mathrm{~V}$ & Indikator Lampu Mati, Solenoid tidak aktif \\
\hline $2 \mathrm{~V}$ & Indikator Lampu Mati, Solenoid tidak aktif \\
\hline $3 \mathrm{~V}$ & Indikator Lampu Mati, Solenoid tidak aktif \\
\hline $4 \mathrm{~V}$ & Indikator Lampu Mati, Solenoid tidak aktif \\
\hline $5 \mathrm{~V}$ & Indikator Lampu Hidup, Solenoid tidak aktif \\
\hline $6 \mathrm{~V}$ & Indikator Lampu Hidup, Solenoid tidak aktif \\
\hline $7 \mathrm{~V}$ & Indikator Lampu Hidup, Solenoid tidak aktif \\
\hline $8 \mathrm{~V}$ & Indikator Lampu Hidup, Solenoid aktif pelan \\
\hline $9 \mathrm{~V}$ & Indikator Lampu Hidup, Solenoid aktif cepat \\
\hline $10 \mathrm{~V}$ & Indikator Lampu Hidup, Solenoid aktif cepat \\
\hline $11 \mathrm{~V}$ & Indikator Lampu Hidup, Solenoid aktif cepat \\
\hline $12 \mathrm{~V}$ & Indikator Lampu Hidup, Solenoid aktif cepat \\
\hline
\end{tabular}


Tabel 5. Pengujian LCD Sebagai Interface Perangkat Keras

\begin{tabular}{|c|c|c|}
\hline No. & Proses & Tampilan LCD \\
\hline 1 & $\begin{array}{l}\text { Saat sistem pertama kali } \\
\text { diaktifkan }\end{array}$ & $\begin{array}{l}\text { "Setting IP Address Audokpora" } \\
\text { "IP Address : 10.0.5.53" } \\
\text { "AUDOCPORA Siap Digunakan" }\end{array}$ \\
\hline 2 & $\begin{array}{l}\text { Saat akses pintu } \\
\text { menggunakan QR code } \\
\text { valid dan button door exit } \\
\text { aktif. }\end{array}$ & $\begin{array}{l}\text { "Access Diterima } \\
\text { Silahkan Masuk" }\end{array}$ \\
\hline 3 & 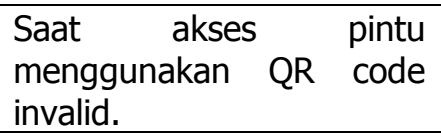 & "Akses Ditolak" \\
\hline
\end{tabular}

Tabel 6. Hasil Pengujian Pengiriman Data Hasil Scan QR Scanner Dan Pembacaan Respon Feedback Dari Server

\begin{tabular}{|c|c|c|c|}
\hline IP & Data Dikirim & Respon Dari Server & Verifikasi Data Scan QR \\
\hline 10.0.5.53 & $\mathrm{db} 08 \mathrm{f} 2$ & $<$ yes $>$ & Data QR Sesuai \\
\hline 10.0 .5 .53 & f642fc & $<$ yes $>$ & Data QR Sesuai \\
\hline 10.0 .5 .53 & 123456 & $<$ no $>$ & Data QR Tidak Sesuai \\
\hline 10.0 .5 .53 & $615 b 0 c$ & $<$ yes $>$ & Data QR Sesuai \\
\hline 10.0 .5 .51 & Ah3456 & $<$ no $>$ & Data QR Tidak Sesuai \\
\hline 10.0.5.51 & $\mathrm{db} 08 \mathrm{f} 2$ & $<$ yes $>$ & Data QR Sesuai \\
\hline 192.168 .1 .82 & f642fc & $<$ yes $>$ & Data QR Sesuai \\
\hline 192.168 .1 .82 & 123456 & $<$ no $>$ & Data QR Tidak Sesuai \\
\hline 10.0 .5 .56 & $615 b 0 c$ & $<$ yes $>$ & Data QR Sesuai \\
\hline 10.0 .5 .56 & Ah3456 & $<\mathrm{no}>$ & Data QR Tidak Sesuai \\
\hline
\end{tabular}

\subsection{Pengujian software}

Pengujian software dilakukan dengan melihat data yang masuk ke database saat pengguna untuk generate $Q R$ code pada aplikasi POCKET ITERA dan pengujian pada tampilan aplikasi door lock di POCKET ITERA. Hasil pengujian database dapat dilihat pada Gambar 7 dan hasil pengujian tampilan aplikasi door lock dapat dilihat pada Tabel 7. 


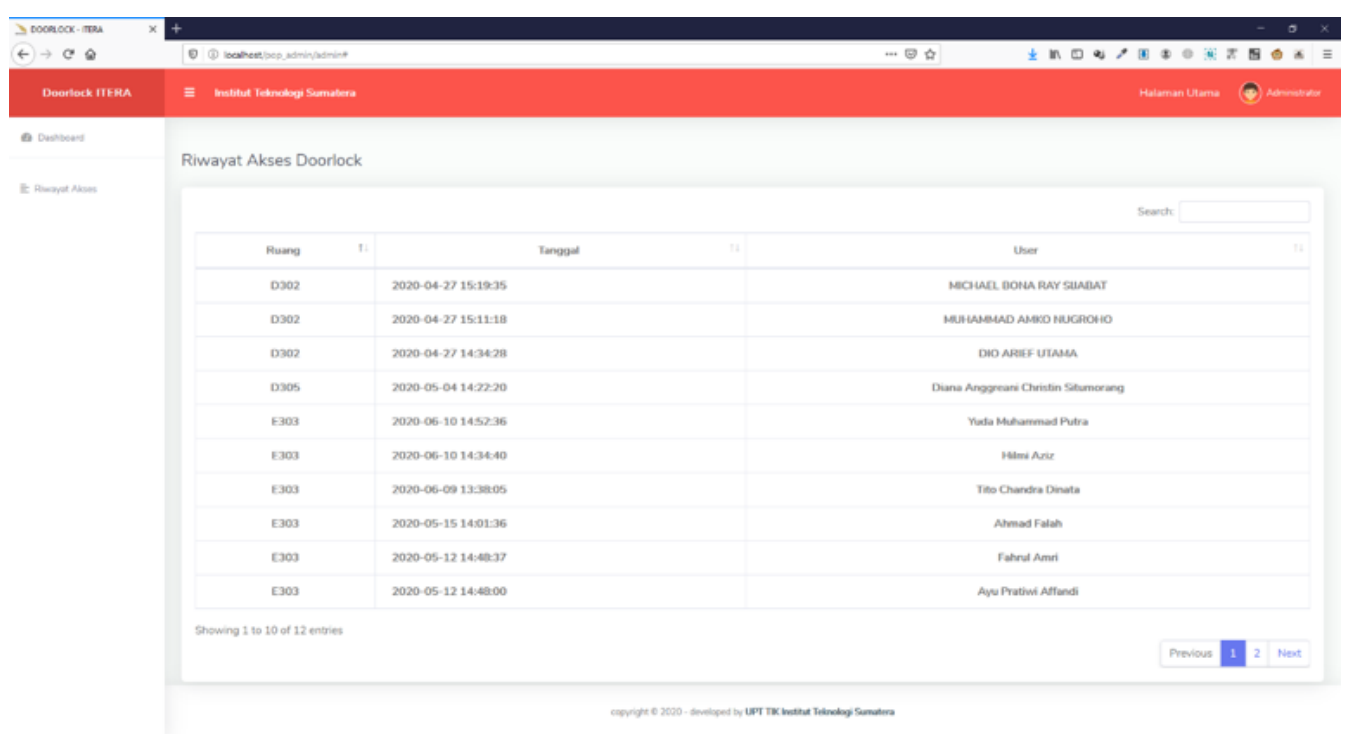

Gambar 7. Hasil Pengujian Data yang Masuk ke Database

Tabel 7. Hasil Pengujian Interface Aplikasi Door Lock Di POCKET ITERA

\begin{tabular}{|c|c|c|}
\hline No. & Proses & Tampilan aplikasi \\
\hline 1 & $\begin{array}{l}\text { Tampilan saat di menu more apps } \\
\text { POCKET ITERA }\end{array}$ & 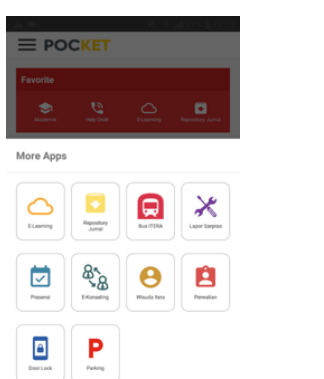 \\
\hline 2 & $\begin{array}{l}\text { Tampilan menu kelas pada saat } \\
\text { aplikasi door lock dibuka. }\end{array}$ & 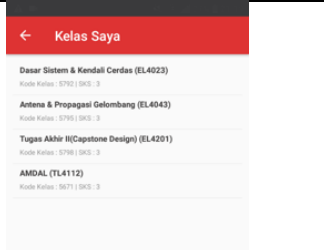 \\
\hline 3 & $\begin{array}{l}\text { Tampilan Saat pengguna menekan } \\
\text { tombol generate saat jam kelas } \\
\text { telah dibuka pada aplikasi door lock. }\end{array}$ & 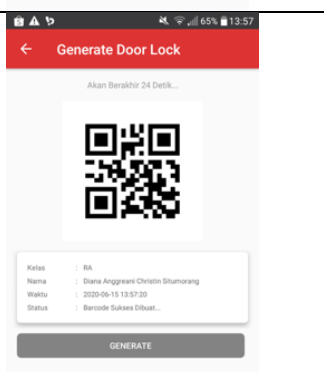 \\
\hline
\end{tabular}




\begin{tabular}{|l|l|l|}
\hline No. & \multicolumn{1}{|c|}{ Proses } & Tampilan aplikasi \\
\hline 4 & $\begin{array}{l}\text { Tampilan Saat pengguna menekan } \\
\text { tombol generate namun jam kelas } \\
\text { masih tertutup pada aplikasi door } \\
\text { lock. }\end{array}$ & $\leftarrow$ Generate Door Lock \\
\hline
\end{tabular}

\subsection{Analisis Sistem Hardware}

Pengujian pertama yakni pengujian hasil scan $Q R$ code untuk membuka pintu, hasil pengujian ini dapat dilihat pada Tabel 1 . Hasil tersebut menunjukan bahwa sistem bekerja sesuai dengan fungsi yang diharapkan. Hal ini dibuktikan dengan hasil scan sistem buka kunci menggunakan sensor $Q R$ scanner GM-65 yang menunjukan hasil yang sama dengan hasil scan $Q R$ code secara manual menggunakan smartphone. Selain itu hal lain yang menujukan bahwa sistem $Q R$ scanner yang dibangun berjalan sesuai fungsinya yakni sistem dapat membuka kunci pintu ketika $Q R$ code yang digunakan valid dan sistem tidak membuka kunci pintu ketika $Q R$ code yang digunakan invalid atau tidak sesuai dengan $Q R$ code diizinkan.

Pengujian kedua yakni pengujian hasil dari trigger yang pada button door exit. Pada pengujian ini diperoleh hasil seperti pada Tabel 2. Dari hasil pengujian tersebut terlihat bahwa hasil yang diperoleh menunjukan bahwa saat trigger button diberikan LOW atau ditekan maka akses valid sehingga door lock terbuka. Kemudian pada trigger button terdeteksi $H I G H$ atau tidak ditekan maka sistem tidak melakukan respon apapun. Dengan demikian sistem button door exit yang dibuat untuk membuka pintu berjalan sesuai dengan fungsi yang diharapkan.

Pengujian ketiga yakni pengujian penggerak door lock dan notifikasi saat pintu diakses menggunakan $Q R$ code dan button exit door. Pada pengujian notifikasi diperoleh hasil seperti pada Tabel 3, dari tabel tersebut terlihat bahwa ketika pintu diakses menggunakan baik menggunakan $Q R$ code atau button exit door ketika akses yang digunakan valid ataupun invalid, buzzer berhasil mengeluarkan bunyi sesuai akses yang terbaca. Selanjutnya dari hasil pengujian pada Tabel 4 terlihat bahwa ketika tegangan yang diberikan pada rentan $1 \mathrm{~V}-4 \mathrm{~V}$ solenoid belum aktif, kemudian pada rentang $5 \mathrm{~V}$ sampai $7 \mathrm{~V}$ lampu indikator solenoid menyala namun solenoid belum bekerja, dan pada tegangan antara $8 \mathrm{~V}-12 \mathrm{~V}$ lampu indikator door lock telah aktif dan solenoid sudah bekerja. Hal ini menunjukan bahwa tegangan minimum yang dibutuhkan untuk dapat mengaktifkan solenoid door lock yakni sebesar $8 \mathrm{~V}$. Berdasarkan kedua hasil pengujian pada penggerak door lock dan notifikasi diatas menunjukan bahwa sistem penggerak dan notifikasi dapat bekerja sesuai dengan fungsi yang diinginkan. 
Pengujian keempat dilakukan untuk melihat hasil dari tampilan LCD yang digunakan sebagai antarmuka perangkat keras. Hasil pengujian ini dapat dilihat pada Tabel 5 , dari hasil pengujian LCD diatas terlihat bahwa LCD berhasil menampilkan karakter ASCII sesuai dengan yang telah diatur pada source code sistem yang dibuat. Hal ini menunjukan bahwa interface perangkat keras yang dibuat telah berfungsi dengan baik dan sesuai dengan yang diharapkan. Hasil pengujian hardware yang terakhir yakni pengujian modul Ethernet w5100. Hasil pengujian ini dapat dilihat pada Tabel 6, dari tabel tersebut terlihat modul Ethernet w5100 dapat mengirimkan data ke server serta menerima respon feedback dari server dengan benar, yakni ketika data yang dikirim valid maka modul Ethernet menerima respon feedback berupa "<yes $>$ " sedangkan jika data yang dikirim invalid maka modul Ethernet menerima respon feedback berupa "<no>". Hal ini menunjukan bahwa komunikasi sistem hardware ke database berjalan dengan baik.

\subsection{Analisis Sistem Software}

Pengujian sistem Software terdiri atas pengujian database dan pengujian Interface aplikasi door lock di POCKET ITERA. Untuk hasil pengujian database dapat dilihat pada Gambar 8. Gambar tersebut menunjukan riwayat akses door lock untuk pengujian database dengan data $Q R$ code. Dari gambar tersebut dapat terlihat bahwa ketika pengguna men-generate $Q R$ code untuk membuka kunci pintu kelas maka database akan menampilkan data berupa kelas yang diakses, waktu akses dan nama mahasiswa/dosen yang mengakses kelas tersebut. Hal ini menunjukan bahwa sistem database dapat berjalan sesuai fungsinya. Kemudian untuk hasil pengujian interface aplikasi door lock dapat dilihat pada Tabel 7, dari tabel tersebut terlihat bahwa saat aplikasi door lock dijalankan tampilan aplikasi memberikan keluaran yang sesuai dengan tampilan yang diharapkan. Hal ini menunjukan bahwa aplikasi door lock berjalan dengan baik di aplikasi POCKET ITERA.

\section{KESIMPULAN}

Penelitian ini menghasilkan rancangan hingga pengujian sistem kunci pintu otomatis pada kelas perkuliahan berbasis Android yang terintegrasi dengan Siakad. Hasil pengujian menunjukkan bahwa alat dapat bekerja secara optimal sesuai dengan fungsi yang diharapkan baik dari sisi hardware maupun software. Hal ini dibuktikan dengan berfungsinya semua komponen hardware dan fitur-fitur pada software yang diuji. Hasil pengujian menunjukkan bahwa hanya pengguna yang berhak saja yang dapat mengakses kelas sesuai dengan jadwal yang telah disusun oleh pihak akademik pada aplikasi Siakad sehingga dapat mengurangi terjadinya tindak pemakaian ruang kelas tanpa izin dari pihak akademik dan meningkatkan keamanan kelas jika sistem buka kunci pintu otomatis ini nantinya dipasang pada tiap-tiap ruang kelas perkuliahan yang ada di kampus ITERA.

\section{DAFTAR RUJUKAN}

Asad, M. R., Nurhayati, O. D., \& Widianto, E. D. (2015). Sistem Pengamanan Pintu Rumah Otomatis via SMS Berbasis Mikrokontroller ATMega328P. Jurnal Teknologi Dan Sistem Komputer, 3(1), 1-7. https://doi.org/10.14710/jtsiskom.3.1.2015.1-7 Blasinski, H., Bulan, O., \& Sharma, G. (2013). Per-colorant-channel color barcodes for 
mobile applications: An interference cancellation framework. IEEE Transactions on Image Processing, 22(4), 1498-1511. https://doi.org/10.1109/TIP.2012.2233483

Guntoro, G., Costaner, L., \& Sutejo, S. (2017). Pelatihan Sistem Pembelajaran ELearning Pada Sekolah Menengah Kejuruan Dwi Sejahtera Pekanbaru. Dinamisia: Jurnal Pengabdian Kepada Masyarakat, Vol. 1, pp. 39-45. https://doi.org/10.31849/dinamisia.v1i1.411

Hangzhou, G. (2016). GM65 Bar Code Reader Module User Manual. Hangzhou: Grow. Iskandar, A., Muhajirin, M., \& Lisah, L. (2017). Sistem Keamanan Pintu Berbasis Arduino Mega. Jurnal Informatika Upgris, 3(2), 99-104. https://doi.org/10.26877/jiu.v3i2.1803

Juniawan, F. P., \& Sylfania, D. Y. (2019). Prototipe Sistem Keamanan Rumah Menggunakan Kombinasi Sensor Dan Sms Gateway. Jurnal Teknoinfo, 13(2), 78. https://doi.org/10.33365/jti.v13i2.304

Lonika, T., \& Hariyanto, S. (2019). Simulasi Smart Door Lock Berbasis QR Code Menggunakan Arduino Uno pada Penyewaan Apartemen Online. 1, 9-15.

Robotshop. (2015). Arduino Mega 2560 Datasheet. Retrieved from http://www.robotshop.com/content/PDF/ArduinoMega2560Datasheet.pdf Saghranie Daulay, S. (2011). Hubungan BARCODE dengan Produk Industri Sebagai Standar Perdagangan Produk Industri Masa Kini Oleh. Journal of Pragmatics, 43(1), 314-326.

Tutorialpoint. (2014). Android Application Development. In Tutorials Point. Retrieved from https://store.tutorialspoint.com 